\title{
REVIEW \\ FLAVINS AS PHOTORECEPTORS OF BLUE LIGHT AND THEIR SPECTROSCOPIC PROPERTIES
}

\author{
HANNA GRAJEK \\ Department of Physics and Biophysics, University of Warmia and Mazury in Olsztyn, \\ Oczapowskiego 4, 10-719 Olsztyn, Poland
}

Received December 12, 2011; accepted December 23, 2011; published online December 30, 2011

\begin{abstract}
This review describes 1) the development of studies on flavin photoreceptors as blue light photoreceptors in many living organisms: their kinds and functions; 2) the studies on spectroscopic properties of flavins, both their dimers and monomers; 3) nonradiative excitation energy transport in the presence of monomers and fluorescent/nonflurescent FMN dimers (excitation traps). The existence equilibrated luminescent FMN centers, energy migration and excitation sink to FMN dimers are taken into account.
\end{abstract}

\section{INTRODUCTION}

Flavins (FMN - flavin mononucleotide, FAD Flavinadenin dinucleotide, $\mathrm{R}$ - riboflavin) (Fig.1) play extremely important biological role in oxireduction reactions taking place in respiratory chain, Krebs cycle, in pirogronian dehydrogenase system and other reactions (Stryer, 1995).

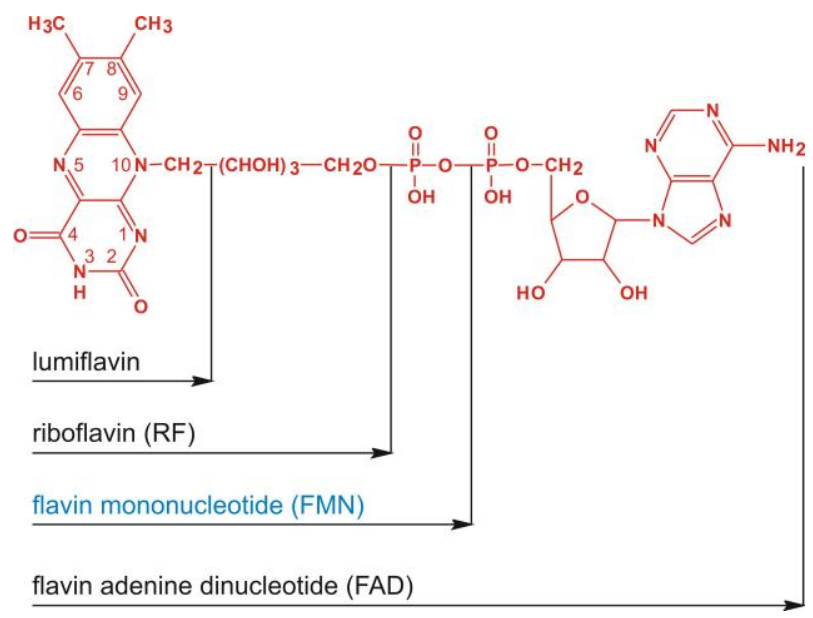

Fig.1.Chemical structure of flavins (based on Fg.1. by Grajek, 2007).

In natural biological structures flavins bind to peptide forming complexes known as flavinproteins, the most important part of which are flavin enzymes. Flavins as a part of enzymes take part in proton and electron transfer, leading among others finally to energy conversion in the organism. Reactions connected with the presence of falvins occur also in mitochondrial membranes, in cytoplasm and other parts of living organisms cells.

The second important function of flavins is their action as photoreceptors of blue light. Flavins absorb light in ultraviolet and visible spectral range. In the excited state they undergo easily photooxidation reactions which make them excellent candidates for playing a role of photoreceptors in different processes connected with the reaction of plants towards light. For example, through flavin enzymes light can regulate photosynthetic carbon and nitrogen metabolism. Excited flavins take part in the reactions of photorespiratory and nitrate reduction pathways. Flavins as photoreceptors take part also in the reactions of chloroplast translocations upon the effect of irradiation by light and in phototropic reactions. They take also part in the process of plants respiration. The action spectrum for the enhancement of respiration by light of the yellow Chlorella mutant (Kowallik, 1967; Kowallik \& Kowallik, 1969) exhibits its maximum at $460 \mathrm{~nm}$ and $375 \mathrm{~nm}$, similarly to the phototropism action spectrum and is also close to the absorption spectrum of flavins. Flavins excited to the triplet state take part in reaction catalized by flavin enzymes.

The photoreception phenomenon is widely studied in two directions. The first one concerns identification of the dye responsible for photoreception. The second one concerns investigation in which way information transferred by light is transformed in the cell and leads to a given morphogenetic process (morphogenesis - all reactions leading to the development of plants: 
germination, growth, flowering etc.) or the movement reaction. These mechanisms are still not fully understood.

The aim of the present review is to show the development of studies on flavin photoreceptors, their current state, and in particular to draw the attention of scientific community to the investigations of spectral properties of monomers and dimers of flavins as well as excitation energy transport with the participation of flavin dimers. Such information can be very helpful in the explanation of the mechanism of photoreception processes in which flavins take part.

\section{CHARACTERISTICS OF FLAVIN PHOTORECEPTORS}

The potential role of different dyes as blue light protoreceptors was a subject of controversy in seventies and eighties. This subject concerned the role of carotenoids, flavins and pterine (Presti, Hsu \& Delbrück, 1977; Ninnemann, 1980; Quiñones \& Aparicio, 1990). As early as in 1975 Zurzycki (1975) has shown that the action spectrum of chloroplasts motion occurring upon the effect of light in the cell of Funaria is similar to that of flavin absorption (Zurzycki, 1975). This unknown blue light photoreceptor has been named then cryptochrome (Cry). To identify which dye is hidden under cryptochrome name the action spectra of numerous biological processes induced by blue light have been measured: DNA photoreactivation, chloroplasts motion, germination of fern spores, phototropism of plants, circadian rhythm in plants etc. The authors have shown that the action spectra of many organisms reflect more absorption spectra of flavins than those of carotenoids (Ninnemann, 1980; Haupt \& Wagner, 1984; Quiñones et al.,1990). Gabryś has proved in many papers based on action spectra of chloroplast rotation in the alga Mougeotia that the role of cryptochrome is played by a flavin (Gabryś, Walczak \&Haupt, 1985; Gabryś, 1986; Walczak, Gabryś, \& Haupt, 1984).

Many other authors indicated also flavins as photoreceptors of blue light (Ninnemann, 1980, Lenci, Colombetti \& Häder, 1983; Schmidt, 1984; Haupt et al. 1984; Löser \& Schäfer,1986, Quiñones, et al., 1990). Figure 2 shows the action spectra of several organisms presented originally in the work of Ninnemann (1980). Visible maxima correspond to the location of flavin absorption band maximum. Moreover, the action spectra possess a characteristic shoulder at the excitation wavelength close to $480 \mathrm{~nm}$.

Rapid progress in the studies of photoreceptors started in 1993 with the initiation of genetic studies, which proved that the first cryptochrome Cry1 is the flavin (FAD). Next, the second flavin photoreceptor Cry2 has

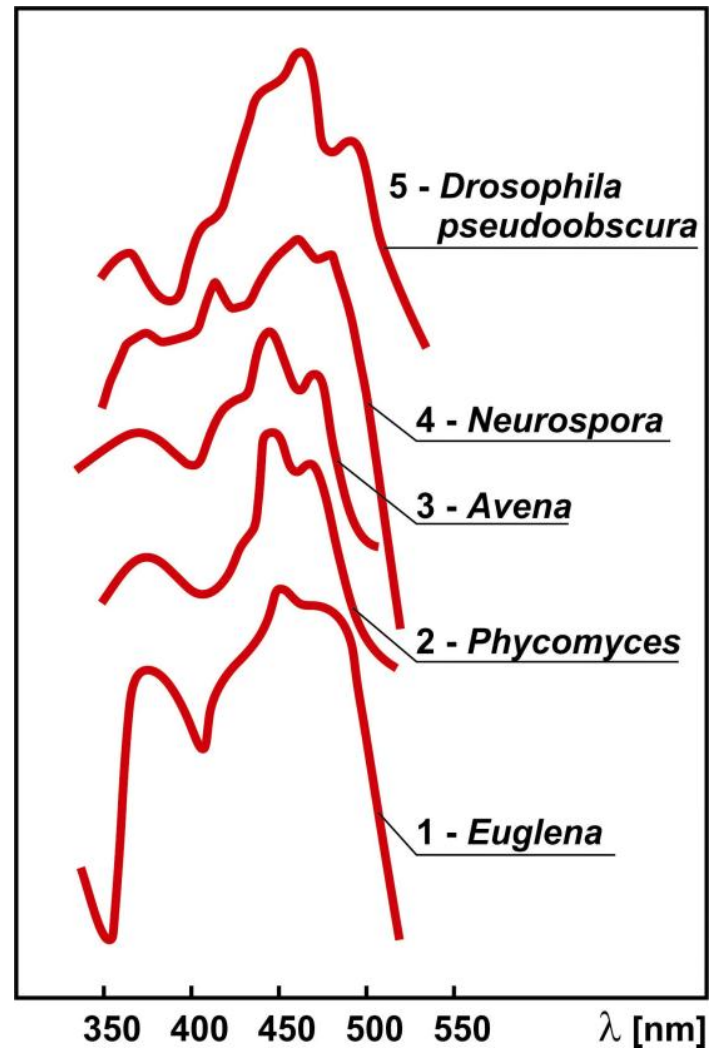

Fig.2. Selected action spectra for various blue light responses from Ninnemann (1980): phototaxis of Euglena (1), phototropism of Phycomyces (2) and Avena (3), photoinhibition of expression of circadian conidation rhytm of Neurospora (4), photoinduced delay shift of the circadian eclosion rhythm of Drosophila pseudoobscura (5), (based on Fig. 1 by Ninnemann, 1980).

been discovered, which differed from the first one by the group binding the chromophores. At present several groups of flavin photoreceptors have been identified: cryptochromes, phototropins, BLUF photoreceptors, ZTL, FKF1 and LKP2 family of photoreceptors.

\section{Cryptochromes}

Cryptochromes are flavin photoreceptors, which regulate the grow and circadian rhythms generated by light in living organisms from bacteria and plants through human being (Partch, Clarkson, Ozgur, Lee \& Sancar, 2005). They act as an integral part of central circadian oscillator in animal brains (so called molecular clock). They control also photomorphogenesis as receptors in plants reply to to blue light or UV radiation (Lin \& Todo 2005). The peptide part of cryptochromes exhibits strong similarity of aminoacid sequence to photolyase - enzymes stimulated by light, which repair DNA. Plant and animal cryptochromes possess from 30 to 250 aminoacidic residues from $\mathrm{C}$-terminal domains of the peptide chain (Partch et al., 2005). Their threedimensional structure is characterized by the presence of 
a domain containing both $\alpha$ and $\beta$ fragments. In the helical domain the access cage for FAD is a catalytic site for photolyase. It is thought that this part of a peptide is extremely important in the mechanism of cryptochromes action. (Lin et al., 2005). Studies on functions and cryptochromes actions are very extensive (Lin, Yang., Guo, Mockler, Chen \& Cashmore, 1998; Devlin \& Kay, 1999; Guo, Duong, Ma \& Lin, 1999; Lin, 2000). The same concerns molecular and biochemical differences between Cry1 and Cry2 (Zhu \& Green, 2001) and conformational changes of cryptochromes upon irradiation by light (Partch et al., 2005). The studies have concerned the photocycle of the cryptochrome photoreceptors (Liu B., Liu H., Zhong \& Lin., 2010).

\section{Phototropins}

Later discovered flavin photoreceptors have been phototropins. This is a plant photoreceptor family of blue light and UV-A radiation (Briggs \& Olnej, 2001) containing among others two types of photoreceptors Phot 1 and Phot 2 involved in phototropism, blue lightinduced chloroplast relocation, stomatal opening and the inhibition of hypocotyl elongation. Phototropin possesses two domains at the N-termini called LOV1 and LOV2 each of them being a binding site for the FMN flavin. Their $\mathrm{C}$ termini contain, in turn, a serine/threonine protein kinase domain.

These are peptides regulated by the signals: light oxygen- voltage. This forms the origin of LOV name (Light, Oxygen, Voltage). The properties of LOV1 and LOV2 domains have been thoroughly studied by Salomon and coworkers (Salomon, Chistie, Knieb, Lempert \& Briggs 2000). LOV domains have the main absorption maximum at $360 \mathrm{~nm}$ and $450 \mathrm{~nm}$ as well as they exhibit their vibronic structure at $425 \mathrm{~nm}$ and 475 $\mathrm{nm}$. These spectra are similar to phototropism action spectra in higher plants. LOV1 and LOV2 domains contain five $\beta$-sheets and two $\alpha$-helices as basic elements of their secondary structure (Salomon et al., 2000). From roentgenographic studies Crosson and Moffat (2001) have defined the LOV2 domain structure of phototropin module of fern photoreceptor Adiantum phy3, containing FMN in the peptide cage. They proved that due to the irradiation by blue light FMN covalently binds to cysteine. Sakai et al. (Sakai, Kagawa, Kasahara, Swartz, Christie, Briggs, Wada \& Okada, 2001) proved that FMN binds in Arabidopsis in a noncovalent way within two LOV domains. They studied carefully the functioning of those photoreceptors not only in phototropism but also in chloroplasts movement upon light. The action of Phot 2 photoreceptor as a controller of chloroplasts movement have been also shown by Jarillo et al (Jarillo, Gabryś, Capel, Alonso, Ecker \& Cashmore, 2001). Widely discussed are the investigations of a photocycle of Flavin-binding domain
LOV with the FMN transformations upon light. These changes concern photoinduced FMN-cysteine adduct formation (Swartz, Corchnoy, Christie, Lewis, Szundi, Briggs \& Bogomolni, 2001; Fedorov, Schlichting, Hartmann, Domratcheva, Fuhrmann \& Hegemann, 2003; Durr, Salomon \& Rüdiger, 2005; Kottke Heberle, Hehn, Dick \& Hegemann, 2003; Schüttrigkeit Kompa, Salomon, Rüdiger\& Michel-Beyerle,2003; Tyagi, Penzkofer, Mathes \& Hegemann, 2010). The authors show that the triplet state of FMN is responsible for the formation of flavin-cysteine adduct.

Kottke et al. (2003) describes the mechanism of reactions of LOV1 (Chlamydomonas reinhardtii ) changes in the following way. The photoexcitation of the dark form of LOV1-447 causes the FMN transition to the excited singlet state, from which the intersystem crossing transition takes place to the triplet state of FMN (LOV1-715). This state assumes two forms: LOV1-715a and LOV1-715b. The first form transforms into LOV1390 form within $800 \mathrm{~ns}$, whereas the second one either transforms into that form directly within 4 microseconds or through LOV1-715a form. The formation of LOV1390 is accompanied by the adduct formation (C(4a)-S and $\mathrm{N}(5)-\mathrm{H})$ FMN-cysteine, which degradates to the the dark of LOV1-445 during the reverse reaction. The studies of kinetics of photoproducts formation of LOV domains phot1 and phot2 have also been performed (Kasahara, Swartz, Olney, Onodera, Mochizuki, Fukuzawa, Asamizu, Tabata, Kanegae, Takano, Christie, Nagatani \& Briggs, 2002).

\section{BLUF ptotoreceptors}

BLUF is a class of blue light photoreceptors. These are AppA flavoproteins possessing domains which bind FAD. The corresponding coding sequences have been found in genomes of photosynthetic bacteria, cyanobacteria and Euglena (Fukushima, Okajima, Shibata, Ikeuchi \& Ithon, 2005). AppA flawoprotein acts under the blue light effect as an antirepressor of a photosynthesis gene expression in the purple bacterium Rhodobacter sphaeroides (Kraft, Masuda, Kikuchi, Dragnea, Tollin, Zaleski \& Bauer, 2003). The studies of Rhodobacter sphaeroides flavoproteins have shown that AppA contains two domains, a Cys-rich carboxylterminal domain responsible for the isomerization of disulfide bond in PpsR and an amino-terminal domain which noncovalently binds the blue-light-absorbing chromophore FAD. These studies have shown the photoreactivity of that domain (Masuda \& Bauer, 2002; Kraft et al., 2003). The investigations of AppA domain photocycle have also been widely made (Fukushima et al., 2005; Kraft et al 2003; Zirak, Penzkofer, Hegemann \& Mathes, 2007). Gauden et al. (Gauden, Yremenko, Laan, van Stokkum, Ihalainem, van Grondelle, Hellingwerf \& Kennis; 2005) have shown that both singlet and triplet states of excited FAD participate in 
this photocycle. The studies of AppA domains with Roentgen radiation (Anderson Dragnea, Masuda, Ybe, Moffat \& Bauer, 2005) indicate that the photoactivation can induce the reorganization in binding flavins with the peptide.

\section{The ZTL, FKF1, LKP2 family of photoreceptors}

The ZEITLUPE (ZTL) photoreceptors, Flavin-binding Kelch F-box1 (FKF1) and LOV Kelch Protein 2 (LKP2) proteins is a novel family of blue-light photoreceptors involved in modulation of the circadian clock and regulation of flowering ( Demarsy \& Fankhauser, 2009; Banerjee \& Batschauer, 2005). These photoreceptors function in Arabidopsis and possess the N-terminal LOV domain followed by F-box moiety, and the Cterminal six Kelch repeats. The LOV domain of these peptides binds FMN chromophore and possesses similar photochemical properties like phototropion LOV domains. The Kelch forms four to six tandem repeats yielding a $\beta$-propler and may serve as the proteinprotein interaction domain that recruits specific proteins for degradation. The degradfation response could also be light regulated (Banerjee et al., 2005). FKF1 leads to the expression of $\mathrm{CO}$, a central element of day-lenthregulated flowering (Turck, Fornara \& Coupland, 2008). $\mathrm{CO}$ transcription is regulated by day length while the protein is unstable in the dark and stabilized during the day (Turck et al., 2008; Demarsy et al., 2009). FKF1 regulates the stability of Cycling Dof Factor 1 (CDF1), which directly represses $\mathrm{CO}$ expresion. The LOV domain of FKF1 interacts with a plant-specific protein called GIGANTEA (GI), which is another positive regulator of $\mathrm{CO}$ expression. This interaction occurs upon blue light irradiation and it depends on the photoexcitation of LOV domain. ZTL interacts also specifically with GI during photoexcitation. GI expresion is clock controlled, thus this light-regulated interaction explains diurnal regulated accumulation of ZTL protein despite constitutive RNA expression.

At present the studies on flavin photoreceptors develop very dynamically. Rapid progress can be observed in the identification and characterization of photoreceptors, their structure and unusual photochemistry as well as their functioning (Briggs, Christie \& Salomon 2001; Briggs et al., 2001, Demarsy et al., 2009). Photocycles are proposed during which FMN and FAD undergo transformations. However, the mechanism of signal transduction in photoreception phenomena in which flavins participate is far from being fully known.

\section{SPECTRAL AND STRUCTURAL PROPERTIES OF FLAVIN PHOTORECEPTORS}

Flavins and their photochemistry have been the subject of intensive studies for about eighty year (Kautsky\& Bruijn 1931; Kuhn \& Weygand 1934; Weber 1948; Flavins and Flavoproteins: 1966, 1968, 1971, 1976; Song 1971; Song, Moore \& Kurtin 1972; Sun, Moore \& Song et, 1972; Siódmiak \& Drabent, 1973; Penzer \& Radda, 1976; Drabent, 1977, 1979; Drabent, Mieloszyk \& Siódmiak, 1984; Müller, 1981; Heelis, 1982). Since the sixties conferences devoted exclusively to flavins have been organized on a regular basis, i.e. ,Flavins and Flavoproteins - International Symposium". In 2011 the 17th International Symposium on Flavins and Flavoproteins took place in at The University of California, Berkeley, USA.

Flavins have been very thoroughly investigated with the spectroscopic techniques. Their absorption, fluorescence, fluorescence excitation, phosphorescence and polarization spectra have been many times measured and their photophysical properties like emission anisotropy, solvatochromism and temperature effect on absorption and luminescence spectra, vibronic structure and intersystem crossing have been elaborated (Beinert, 1960; Kozioł, 1966, 1969; Song, 1971; ScolaNagelschneider\& Hemmerich 1972, Siódmiak \& Frąckowiak, 1972; Song et al., 1972; Sun et al. 1972, Müller et al., 1973; Visser, Ommen, Ark, Müller \& Voors;, 1974; Drabent \& Białłowicz, 1976; Drabent, 1977; Heelis, Parsons B, Phillips \& McKellar, 1978; Heelis 1982; Bystra \& Drabent 1982; Bystra, Drabent \& Szubiakowska, 1983; Drabent et al.,1984; Drabent \& Laczko, 1984; Grajek, Drabent, Żurkowska .\& Bojarski 1984; 1986; 1990; Grajek, Żurkowska, Bojarski P., Kukliński, Smyk, Drabent \& Bojarski C 1998; Grajek, 2003; Grajek, 2007).

Absorption spectra of flavins: FMN, FAD and RF are similar. FMN possesses characteristic absorption maxima at $445 \mathrm{~nm}, 370 \mathrm{~nm}, 265 \mathrm{~nm}$ and $220 \mathrm{~nm}$ as well as the fluorescence band with the maximum around $520 \mathrm{~nm}$ in water solutions and phosphorescence band at around $605 \mathrm{~nm}$ at low temperatures (below $150 \mathrm{~K}$ ) in ethanol. The $\pi-\pi$ character of first two transitions in absorption has been confirmed by theoretical calculations performed using quantum chemical methods (Song, 1969a; Song, 1969b; Grabe 1974, Sun et al., 1972) as well as by experimental data obtained from polarization spectra in the excitation and emission band (Song 1969a; Siódmiak et al., 1972; Song et al., 1972; Sun et al., 1972). Based on the theoretical calculations the existence of two $\pi-\pi$ transitions at 280 $\mathrm{nm}$ and $260 \mathrm{~nm}$ (Sun et al., 1972) has been found. It has been also indicated that they can contribute to the observed maximum at $265 \mathrm{~nm}$. Also the $n-\pi$ transitions are possible in view of four free electron pairs at 
nitrogen and oxygen atoms in the isoalloxazine ring (Sun et al., 1972; Sun \& Song, 1973; Drabent et al.,1976). The spectral location of these transitions is, however, not fully known. Some authors suggest their appearance at $300 \mathrm{~nm}, 370 \mathrm{~nm}$ or $480 \mathrm{~nm}$ (Song 1971; Harders, Förster, Voelter\& Bacher, 1974, Drabent,1979). The location of transition moments in absorption and the angle between them has also been investigated and determined among others by Johanssson et al. (Johansson, Davidson, Lindblom \& Naqvi; 1979) and Eaton et al. (Eaton, Hofrichter, Makinen, Andersen \& Ludwig, 1975). They obtained $\square\left(\overrightarrow{\mathrm{M}}_{I}, \overrightarrow{\mathrm{M}}_{I I}\right)=39^{\circ}$. Many spectroscopic and photochemical properties of flavins have been reported in a review by Heelis (1982), Drabent (1977) and Grajek (2007). The interactions of flavins with aminoacids and aromatic hydrocarbons have been studied in a number of works (Tollin 1968; Flavins and Flavoprotetns 1971; Müller, Mayhew \& Massey, 1973; Song et al.1972; Ulbrych, 1979; Müller, 1981; Bystra 1984; Bystra, Drabent, Szubiakowska \& Smyk, 1985; Mieloszyk, Drabent \& Mieloszyk, 1989; Berg, Hoek \& Visser, 2004). Flavins interact ,stackingly" with the rings of aromatic compounds and aminoacids (Muñoz, Carmona, Hidalgo, Guardado \& Balón, 1995).

Worthy mentioning are the structural studies and conformation dynamics studies of enzymes and flavin coenzymes (Narayanasami, Horowitz \& Master, 1995; Estabrook, Shet, Fisher, Jenkins \& Waterman, 1996; Miura, Maeda Arai, 2001; Guo et al., 2002; Berg \& Visser, 2001). Also the deactivation processes of flavins excited states are studied in view of their use in explanation of reactions dynamics in various biological systems. The formation efficiencies of radical pairs in the photoinduced charge transfer from tryptophan residues HEWL (hen-egg-white lysozyme) to FMN (Miura et al., 2003) have been determined. This latter process is accompanied by the quenching of the FMN singlet state. Two types of triplet state quenching in the FMN-HEWL system have been proposed: quenching through the diffusion of HEWL and FMN and quenching connected with the interaction of HEWL with FMN. Worthy of note are also the studies devoted to photochemical reactions occurring between the FMN in the excited triplet state and aromatic aminoacids (tyrosine, tryptophan and histidine connected with the electron and proton transfer. These investigations have been performed with the time-resolved nuclear magnetic resonance (Tsentalovich, Lopez, Hore \& Tagdeev, 2002) and other methods (Lu \& Liu, 2002). The quenching of the singlet states of flavins is mostly connected with their interactions with the aromatic compounds, aminoacids and peptides (Ulbrych \& Siódmiak, 1982; Mieloszyk et al., 1989; Muñoz et al., 1995) and with the formation of flavin dimers in solutions (Grajek et al:: 1990, 1992; Grajek, Żurkowsk,\& Kuśba, 2005; Grajek,
2007; Bojarski P., Grajek, Żurkowska, Kukliński, Smyk \& Drabent, 1999; Bojarski P, Kułak, Grajek, Żurkowska, Kamińska, Kukliński \& Bojarski C., 2003).

Many biological compounds (Gruszecki, Gagoś \& Hereć, 2003a; Gruszecki, Gagoś, Hereć\& Kernen, 2003b; Gruszecki, Gagoś \& Kernen, 2002; Sujak, Okulski \& Gruszecki 2000; Frąckowiak, Zelent, Malak, Planner, Cegielski, Munger \& Leblanc, 1994; Frąckowiak, Dudkowiak, Ptak, Malak, Gryczyński \& Zelent, 1998; Nowicki, Susla, Planner \& Frąckowiak 1999) like proteins, enzymes, organic dyes and synthetic compounds (e.g. rhodamines) form dimers. Paying attention to many different photoreceptors leads to the conclusion that many photobiological processes take place with the contribution of dimers. For example, the dimers of chlorophyll appear first of all in both photosynthetic centers, both in PS1 and in PS2. Phytochrome and carotenoids act also as dimers in the photoreception phenomena. It follows from these facts that dimers can play a role of incident light traps in many phenomena occurring in living organisms.

\section{INVESTIGATIONS OF FLAVINS DIMERIZATION. FLAVINS DIMERS IN PHOTORECEPTION SYSTEMS.}

The studies of flavins dimerization started in 1956 when Beinert suggested based on the concentration changes of absorption at $900 \mathrm{~nm}$ the formation of a charge-transfer (CT) complex between the oxidized and reduced form of FMN $\left(\mathrm{FMN}_{-\mathrm{FMNH}}\right)$ or the formation of a semiquinone dimer. Similarly, Gibson et al (Gibson, Massey \& Atherton, 1962) studied the mixture of FMN with $\mathrm{FMNH}_{2}$. By recording absorption spectra with the maxima at $570 \mathrm{~nm}$ and $900 \mathrm{~nm}$ they concluded the formation of dimers of the reduced form of $\mathrm{FMNH}_{2}$ flavin and CT complexes. These have not been, however, the studies of oxidized forms of FMN flavin characterized by absorption maxima at $445 \mathrm{~nm}$ and 370 nm. The mentioned authors claimed that FMN dimerization does not affect the absorption maximum at $445 \mathrm{~nm}$. Almost no further investigations have been undertaken concerning FMN dimerization process until the eighties. Meanwhile, only several authors performed relevant studies: Müller et al (1973) observed the temperature changes in absorption spectra due to flavins (and flavins derivatives) dimers. The existence of flavins dimers has also been proposed by Harders et al. (1974), Visser et al. ( 1974) and Heelis et al. (1978). Song et al (1972) based on the phosphorescence excitation spectra at $\mathrm{T}=77 \mathrm{~K}$ suggested extremely weak fluorescence of riboflavin (and its derivative) dimer. The mentioned studies have not been, however, oriented towards the determination of dimerization constant and 
investigation of dimerization process (which is the case of many other aggregating dyes).

In 1968 Sarma et al.(Sarma, Dannies \& Kaplan, 1968) followed by Kainosho \& Kyogoku. (1972) based on NMR studies proposed the models of FMN dimer, in which FMN monomers were aligned "face to face" one above the other and and slightly shifted. These models differ by the shifts of isoalloxazine rings.

Typical studies of FMN dimerization process have been carried out for FMN in water and glycerol-water solution in 1984 and later (Grajek et al.: 1984, 1986; 2001). In these works the effect of dimerization on the absorption spectrum of flavins has been studied. The spectra of pure FMN monomer and dimer as well as the dimerization constant in water have been determined $\left(\mathrm{K}=118.0 \mathrm{M}^{-1}\right.$ at $\mathrm{T}=298.2 \mathrm{~K}$, water $)$ and $\left(\mathrm{K}=20.5 \mathrm{M}^{-1}\right.$ at $\mathrm{T}=298.2 \mathrm{~K}$, glycerol-water mixture, viscosity $056 \mathrm{P}$ ) (Grajek et al. 1984). Strong dependence of absorption FMN spectrum in water on temperature has been found. The dimerization constant changed from $\mathrm{K}=330 \mathrm{M}^{-1}$ at $\mathrm{T}=275.2 \mathrm{~K}$ to $\mathrm{K}=26 \mathrm{M}^{-1}$ at $\mathrm{T}=339.7 \mathrm{~K}$ (Grajek, Żurkowska, Drabent \& Bojarski, 2001). The studies of FMN dimerization have been performed also in a rigid PVA matrix ( $\left.\mathrm{K}=11.6 \mathrm{M}^{-1}\right)$ (Grajek et al., 1998, Grajek 2007), where FMN dimers occurred durable and where the temperature increase even up to $338 \mathrm{~K}$ did not lead to their decomposition.

The FMN dimer structure has been thoroughly defined in water and in a viscous solution (Grajek et al. 1986) as well as in rigid PVA (Grajek et al., 1998; Grajek 2007) based on the spectroscopic studies and Kasha theory. It has been found that FMN dimers form "sandwiches", in which two monomers are aligned "face to face" one above the other at a distance $\mathrm{R}=3.5 \pm 0.3 \AA$ (in water) and $\mathrm{R}=3.2 \pm 0.3 \AA$ (in PVA) in such a way that the ribityl chains are in opposite directions. FMN monomers are slightly mutually twisted so that the $\mathrm{CH}_{3}$ groups do not form a sterical obstacle. The transition moments responsible for the first transition in the absorption band in water form an angle $\alpha_{I}=71 \pm 4^{\circ}$, whereas the moments responsible for the second transition form an angle $\alpha_{\text {II }}=0 \pm 4^{\circ}$. For FMN dimer in PVA the following respective values have been obtained: $\alpha_{\mathrm{I}}=75^{\circ} \pm 4^{\circ}, \alpha_{\mathrm{II}}=$ $0^{\circ} \pm 4^{\circ}$. The hydrophobic interactions are responsible for the binding of izoalloxazine rings. It has been found that the van der Waals interactions bind izoalloxazine rings of flavins through the interaction of $\pi$-electronic system while four water molecules stabilize this dimer through the hydrogen bonds (Grajek et al., 1986). The obtained structure of FMN dimer is in agreement with the analysis of chemical interactions, with the transition moments directions determined by Johansson et al. (1979) and with the NMR studies. FMN dimer structure has been confirmed by the molecular modeling calculations (Smyk \& Grajek 2001).
Such a structure of the FMN dimer has been obtained as a result of the numerical decomposition of dimer absorption spectrum into simpler components. One can see from pure dimer spectrum (Fig.3B) that there appears a shoulder at about $480 \mathrm{~nm}$ which results from the Davidov splitting of the first singlet excited state into two levels: $H$ and $J$ corresponding to the $S_{0} \rightarrow S_{1}$ in the monomer. Hence, two bands $\mathrm{H}$ and $\mathrm{J}$ appear in the dimer spectrum. The comparison between the dimer spectrum and the action spectra for the chloroplast (Fig.3C and Fig.3D) (Zurzycki 1962) one can note greater similarity of action spectra to the FMN dimer absorption spectrum than to that of monomer.
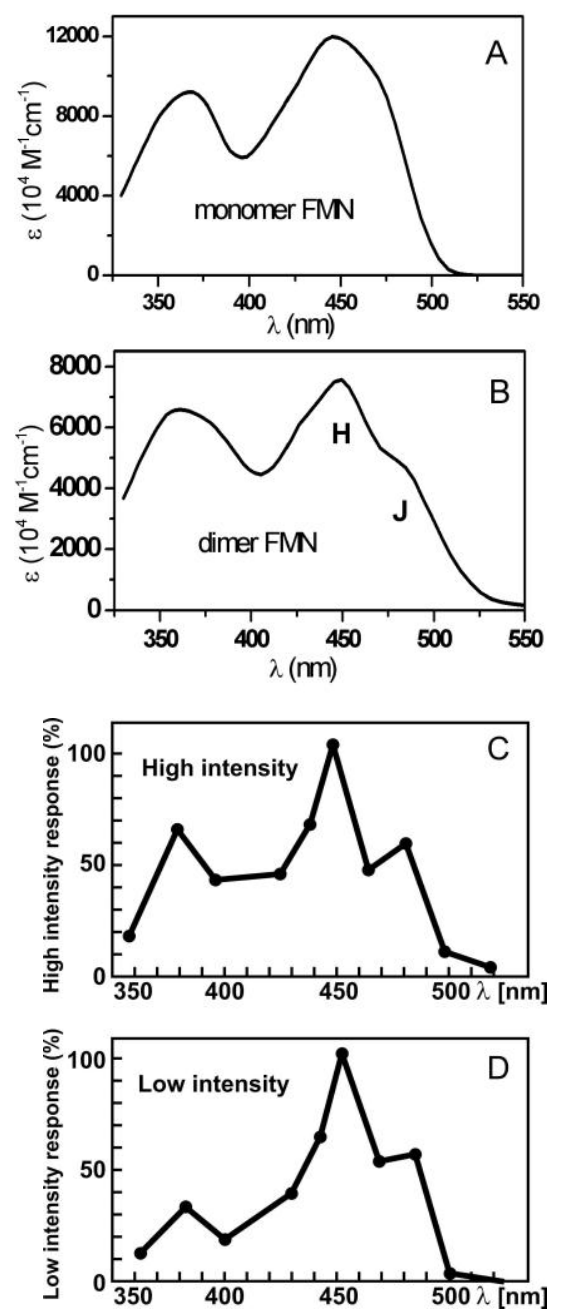

Fig.3. The comparison between FMN monomer and dimer absorption spectra with the action spectra for chloroplast orientations: A - FMN monomer absorption; B - FMN dimer absorption spectrum with the indicated $\mathrm{H}$ and $\mathrm{J}$ bands location corresponding to $S_{0} \rightarrow S_{1}$ transition; $C-$ Action spectra for chloroplast orientation in Lemna trisulca - high intensity, D low intensity: (Fig. 3C and 3D based on Fig. 33 by Zurzycki, 1962). 
This is quite interesting having in mind prolific recent communications on FMN dimers existence in biological organisms and photoreceptors. Recently, Muralidhara and Wittung-Stafshede (2003) confirmed based on the calorimetric studies of isothermic titration, NMR as well as absorption and fluorescence spectroscopy the structure of FMN dimer obtained by Grajek et al. (1986) by discovering the FMN dimer in a flavodoxin protein, the co-factor of which is FMN. They proved the existence of a "stacking" FMN dimers bound with the apoflavodoxin Deslfovibrio desulfuricans. The FMN dimer interacts with three protein loops in such a way that one FMN monomer from the dimer forms a sandwich with the tryptophan Trp 60 and the second one with the tyrosine Tyr 68. This has been the first proof of FMN dimer existence in the biological system. Also Bieger et al. (Bieger, Essen \& Oesterhelt, 2003) based on crystallographic studies proved the existence of six riboflavin dimers in dodecine, a flavoprotein from Halobacterium salinarium.

However, no studies on flavin photoreceptors have been performed until now to find out what is actually a flavin photoreceptor: monomer or dimer of a flavin? In the literature the dimerization of flavins in biological systems still remains an open question. The possibility of a flavin dimers formation in biological systems is possible due to close proximity of flavin monomers as reported in the literature.

Crosson and Moffat (2001) considered the possibility of dimerization between LOV1 and LOV2 domains In a single phototropin molecule. Salamon et al. (Salomon, Lempert \& Rüdiger, 2004) proved the formation of dimers from phototropin fragments with flavin domains LOV1 and LOV2 (without the kinaze part) and have shown that LOV1 domains form dimers in a solution, while LOV2 does not exhibit such a property. The conclusion has been drawn that the phototropin is a dimer and that the LOV1 domain is probably responsible for the dimerization. Nakasako et al. (Nakasako, Matsuoka, Zikihara \& Tokutomi, 2005) studied the dimeric association of photoreceptors regulating the flowering of Arabidopsis and have shown the antiparallel alignment of LOV domains with FMN in a dimer. Also Kitizing et al. (Kitizing K, Fitzpatrick, Wilken Sawa, Bourenkov, Macheroux \& Clausen, 2005) have shown based on crystallographic measurements of flavoproteins YqjM that this is a tetrameric enzyme organized as a dimer of two active dimers. Mutual alignment of FMN monomers in this tetramer has been defined.

It must be herein underlined that the action spectra of chloroplast movement (Gabryś 1985; Gabryś 1986; Gabryś et al., 1985), photaction of Euglena and phototropism of circadian rhythm in Neurospora, the action spectra of b-cytochrome photoreduction in Neurospora (Ninnemann 1980; Galland \& Lipson 1985) as well as the absorption spectra of cryptochrome Cry1 (Whitelam, 1995), LOV domains (Salomon et al 2000; Swartz et al. 2001; Kasahara et al. 2002), FAD binding domains in AppA (Masuda et al. 2002, Kraft et al. 2003) and others shown in Fig.2 are more similar to flavin dimers than to monomers (compare.Fig.2 with Fig.3A and Fig.3B). The characteristic shoulder in the action spectrum at about $480 \mathrm{~nm}$, which exists also in the flavin dimer absorption spectrum (Grajek et al. 1984, 1986, 2001) can indeed suggest that the flavin dimer plays a role of a photoreceptor (despite flavoproteins also possess weakly visible shoulder). Nevertheless, based only on these spectra it would be difficult to undoubtedly state that flavin dimers are photoreceptors in these processes. This is an open problem for further studies of flavins and excitation energy transfer process between them.

Flavins in biological systems appear in rigid environment: peptide structures or membranes so it is justified to study nonradiative excitation energy transfer in FMN monomer - dimer system and the spectroscopic properties of dimers in model rigid media (PVA films). FMN dimers in a rigid medium exhibit their own fluorescence (Grajek et al. 1998; Grajek 2007; Grajek et al. 2007a), which yields the possibility to study energy transfer acts originating from dimers (Bojarski $\mathrm{P}$ et al 2003; Grajek 2007). It has not been possible until now to achieve this for other dyes as at high concentrations they usually form higher order aggregates. FMN, however, does not form higher order aggregates due to sterical effects (Grajek et al., 2001; Grajek 2003; Grajek, Gryczyński I, Bojarski, Gryczyński Z, Bharill \& Kułak, 2007b). Also nonradiative excitation transfer between the monomers and dimers of FMN as well as energy migration between FMN monomers have been studied in liquid solutions (Grajek et al. 1990, 1992, 2005). It occured that in liquid solutions FMN dimers are perfect traps for excitation energy for the exciting light and excitation energy transferred to them from monomers. Qualitative and quantitative investigations of energy transport for FMN have been performed using Bojarski theory (Bojarski \& Domsta, 1971) of multistep excitation energy transport (MEET). It has been found that the energy transfer to the dimer is preceded by energy migration between FMN monomers (Grajek, 1990; 1992). Good correspondence between the theoretical results of concentration quenching of fluorescence $\eta / \eta_{0} \quad$ (Grajek et al., 1990) and concentration depolarization $\mathrm{r} / \mathrm{r}_{0}$ (Grajek, Żurkowska, Bojarski \& Drabent, 1992) with respective experimental data in glycerol-water solutions confirmed multistep excitation energy transport. Experimental studies of FMN quantum yield in water with the application of MEET model (Grajek, Żurkowska \& Kuśba, 2005) have shown an important role of material diffusion in accelerating energy transport and making it more 
efficient. The agreement between the theoretical results of $\eta / \eta_{0}$ of the model extended by Kusba to material diffusion effect (Grajek, et al., 2005) proved that the relative contribution of the diffusion accelerated nonradiative energy transfer to the total drop of the quantum yield can be even higher than 70\%. The analysis has also shown that it is necessary to take into account an additional channel of deactivation of the excitation energy transfer, i.e., its partial degradation during the successive steps of migration between monomers. The probability of such a process can be as large as $0.6-0.7$. However, for FMN in rigid PVA matrix it has been shown that FMN dimers are fluorescent (Grajek et.al., 1998; Grajek 2007; Grajek, Liwo, Wiczk \& Żurkowska, 2007a) and able to transfer energy back to monomers (reverse energy transfer). Indeed, experimental and theoretical studies of energy transport between FMN monomers in rigid matrices have shown the presence of reverse energy transfer from dimers to monomers and the effect of energy migration between FMN dimers. Both hopping model of reverse energy transport (Bojarski C, 1984; Grajek 2007) and self-consistent diagrammatic model (Kułak \& Bojarski, 1995; Bojarski P. et al., 2003) have been applied.

Moreover, these studies have shown the role of excitation energy sink which takes place between the equilibrated FMN centers $\mathrm{M}_{1}, \mathrm{M}_{2}, \mathrm{M}_{3}$, which occurs as a result of inhomogeneous broadening of energy levels

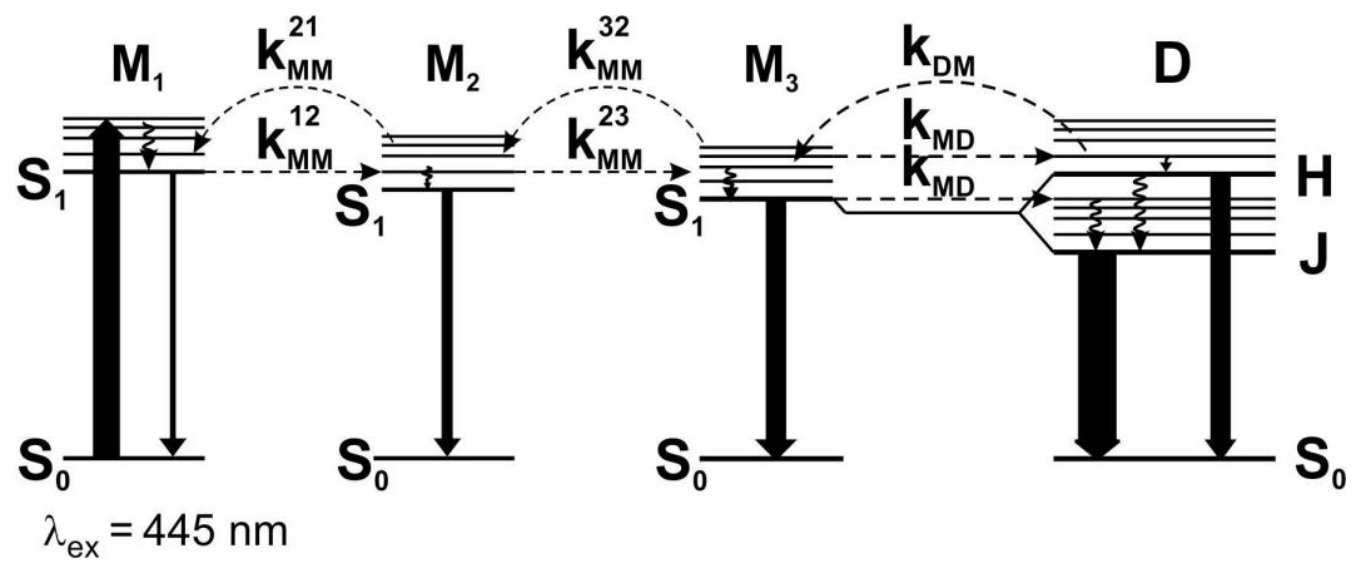

Fig.4. Diagrams of monomer M and dimer D energetic levels for FMN. Any possible ways of energy transfer between FMN monomers and dimers in rigid PVA system are shown. $\mathrm{M}_{1}, \mathrm{M}_{2}, \mathrm{M}_{3}$ - denote monomeric equilibrated centers with decreasing energies of $0-0 . \quad k_{\mathrm{MM}}^{12}$, $k_{\mathrm{MM}}^{23}$ - rate constants for energy migration; $k_{\mathrm{MM}}^{21}, k_{\mathrm{MM}}^{32}$ - rate constants for remigration; $\mathrm{M}^{*} \rightarrow \mathrm{D}$ - directional energy transfer with the rate constant $\mathrm{k}_{\mathrm{MD}}$ and reverse energy transfer $\mathrm{D}^{*} \rightarrow \mathrm{M} \quad$ with the rate constant $k_{\mathrm{DM}}$.

(IBEL). Figure 4 visualizes excitation energy migration among these centers, the directional excitation energy sink from monomers to the dimers $\mathrm{M}^{*} \rightarrow \mathrm{D}$ and the reverse transfer D* $\rightarrow \mathrm{M}$ (from Żurkowska, Grajek H.\& Bojarski, 1996; Grajek et al. 1998; Grajek 2007). This example shows the degree of development of original quantum- mechanical Förster model of single-step energy transfer.Energy transport processes in biological systems may be even more complex (Frąckowiak \& Fiksiński, 1976). By now it has not been shown how exactly energy transfer with the participation of flavins takes place in biological systems. In (Żurkowska et.al., 1996; Grajek et al. 1998; Grajek 2007) it has been shown that for FMN, IBEL extremely strongly affects the tracks of excitation sink. It is an open question if and how biological species would "choose" the most effective tracks for energy transport as already observed in ordinary in vitro FMN rigid systems.

\section{CONCLUSIONS}

Flavins as biological molecules are inspiring to investigate not only for biologists and biochemists but also for physicists. These molecules take part in excitation energy transport effectively. Therefore the number of papers dealing with this subject gradually increases. Flavins participating in the photoreception phenomena transfer energy to the reaction center. It is expected that new valuable information on energy transfer range will be obtained with modern experimental techniques (ultra fast measurements of 
fluorescence decays with time-correlated single photon counting method, up-conversion technique and time resolved emission spectra measurements) when correlated with the theory of nonradiative excitation energy transfer. Such studies are planned among others biochemical reaction. 2) global quantum yields of excitation energy transfer from monomers to dimers and the analogous yields of energy transfer from monomers of particular orders of excitation; 3) global average lifetimes of monomers in the excited state and average residence time of excitation energy on monomers of particular orders of excitation. This will allow for more profound and quantitative investigation of excitation transfer between FMN molecules. Especially important are herein the investigations in the presence of FMN dimers. The use of time resolved techniques will allow that by immediate observations of time evolution of the monomer and dimer emission spectra of FMN it will be possible to confirm existence of fluorescence originating separately from the excited dimer states $\mathrm{H}$ and $\mathrm{J}$, and observe existence of the long-wavelength dimer centers. There is a lack of reports in the literature, related to such type of investigations.

However, the confirmation of hypothesis suggested in this work that in some photoreception phenomena the flavins dimers can play a role of photoreceptors requires further investigations performed directly with the biological material.

\section{ACKNOWLEDGMENTS}

The author would like to thank Professor Halina Gabryś from the Cracow Jagiellonian University for the valuable discussions on biological aspects of this work.

\section{REFERENCES}

Anderson S., Dragnea V., Masuda S., Ybe J., Moffat K. \& Bauer C. (2005). Structure of a novel photoreceptor, the BLUdomain of AppA from Rhodobacter sphaeroides. Biochemistry, 44(22): 7998-8005. Banerjee R. \& Batschauer A. (2005). Plant blue-light receptors. Planta, 220, 498-502.

Beinert H. (1956). Spectral characteristics of flavins at the semiquinoid oxidation level. J. Am.Chem. Soc. 78(20), 5323- 5328.

Berg P.A.W. \& Visser A.W.G. (2001). Tracking molecular dynamics of flavoproteins with time-resolved fluorescence spectroscopy. [In:] Valeur B., Brochon J.C. (eds.) New trends in fluorescence spectroscopy. Applications to chemical and life sciences. Springer-Verlag Berlin Heidelberg, New York, pp.457-485.

Berg P.A.W., Hoek A. \& Visser A.W.G. (2004). Evidence for a novel mechanism of time-resolved flavin fluorescence depolarization in glutathione reductase. Biophysical Journal. 87, 2577-2586. in our group. They will enable to obtain 1) the mean number of excitation jumps since the moment of absorption to the moment of emission in the form of quantum of light or conversion into heat or its loss in a

Bieger B., Essen L.O. \& Oesterhelt D. (2003). Crystal structure of halophilic dodecin: a novel dodecameric flavin binding protein from Halobacterium salinarium. Structure, 11, 375-385.

Bojarski C. \& Domsta J. (1971). Theory of the influence of concentration on the luminescence in solid solutions. Acta Phys. Acad. Sci. Hung., 30, 145-166.

Bojarski C. (1984). Influence of the reversible energy transfer on the donor fluorscence quantum yield in donot-acceptor systems. Z. Naturforsch. 39, 948-951.

Bojarski P., Grajek H., Żurkowska G., Kukliński B., Smyk B. \& Drabent R. (1999). Excitation energy transport concentrated system of flavomononucleotide in polyvinyl alcohol films, J. Fluorescence 9, 391-396.

Bojarski P., Kułak L., Grajek H., Żurkowska G., Kamińska A., Kukliński B. \& Bojarski C. (2003). Excitation energy transport and trapping in concentrated solid solutions of flavomononucleotide. Biophys. Biochim. Acta, 1619, 201208.

Briggs W.R., Christie J.M. \& Salomon M. (2001). Phototropins: a new family of flavin-binding blue light receptors in plants. Antioxid. Redox Signal, 3(5), 775-788.

Briggs W.R. \& Olnej M.A. (2001). Photoreceptors in plant photomorphogenesis to date. Five phytochromes, two cryptochromes, one phototropin, and one superchrome. Plant. Physiol., 125, 85-88.

Bystra K. \& Drabent R. (1982). Zmiany elektronowych widm flawin pod wplywem matrycy polimerowej. Zesz. nauk. ART. Olszt. Technologia Żywności, 17, 63-68.

Bystra K., Drabent R., Szubiakowska L. \& Smyk B. (1983). Spectral properties of flavins in hydrophilic matrices. Spectrosc. Lett., 16(7), 513-530.

Bystra K. (1984). Badania spektralne flawinowych grup prostetycznych. Zag. Biofiz. Wspótcz., 9, 153-177.

Bystra-Mieloszyk K., Balter A. \& Drabent R. (1985). Fluorescence Quenching for flavins interactiing with egg white riboflavin-bonding protein. Photochem and Photobiol., 4(2), 141-147.

Crosson S. \& Moffat K. (2001). Structure of a flavin-binding plant photoreceptor domain: Insights into light-mediated signal transduction. Proc. Natl. Acad. Sci.USA, 98, 6, 29953000.

Demarsy E. \& Fankhauser C. (2009). Higher plants use LOV to perceive blue light.Current Opt. in Plant Biol. 12, 69-74

Devlin P.F. \& Kay S.A. (1999). Cryptochromes - bringing the blues to circadian rhythms. Trends Cell Biol., 9, 8, 295-298.

Drabent R. \& Białłowicz J. (1976). Types of electronic transitions responsible for riboflavin absorption. Bull. Acad. Pol. Sci., 24(11), 1055-1061.

Drabent R. (1977). Właściwości optyczne ryboflawiny w układzie modelującym struktury biologiczne. Zesz. nauk. ATR Olszt. Technologia Żywności, 11, 3-49.

Drabent R. (1979). Transition moments of riboflavin in the 300 nm region. Acta Phys. Pol., A55(3), 371-375. 
Drabent R. \& Laczko G. (1984). Delayed fluorescence of the flavomononucleotide complex. Acta Biochim.et Biophys. Acad. Sci. Hung. 19(3-4), 263-272.

Drabent R. Mieloszyk J. \& Siódmiak J. (1984). Delayed fluorescence and fosfoerscence of the flavomononucleotide stabilized by poly(vinyl alcohol) matrix. Acta Biochim.et Biophys. Acad. Sci. Hung. 19(3-4), 259-264.

Durr H., Salomon M. \& Rüdiger W. (2005). Chromophore exchange in the LOV2 domain of the plant photoreceptor phototropin1 from oat. Biochemistry, 44(8), 3050-3055.

Eaton W.A., Hofrichter J., Makinen M.W., Andersen R.D. \& Ludwig M.L. (1975). Optical spectra and electronic structure of flavine mononucleotide in flavodoxin crystals. Biochemistry, 14, 10, 2146-2151.

Estabrook R.W., Shet M.S., Fisher C.W., Jenkins C.M. \& Waterman M.R. (1996). The interaction of NADPH-P450 reductase with P450: an electrochemical study of the role of the flavin mononucleotide-binding domain. Arch. Biochem. Biophys., 333, 1, 308-315.

Federov R., Schlichting I., Hartmann E., Domratcheva T., Fuhrmann M. \& Hegemann P. (2003). Crystal struktures and molecular mechanism of a light-induced signaling switch: The Phot-LOV1 domain from Chlamydomonas reinhardtii. Biophys. J., 84, 2474-2482.

Flavins and Flavoproteins, (1966). Slater E.C (ed). Elsevier Publishing Company, Amsterdam-London-New York, B.B.A. Library-vol. 8.

Flavins and Flavoproteins, (1968). Yagi K.(eds.) The Proceedings of the $2^{\text {nd }}$ Conference on Flavins and Flavoproteins. University of Tokyo Press, Tokyo.

Flavins and Flavoproteins. (1971). Kamin. H. (ed.) University Park Press, Baltimore, $3^{\text {rd }}$ International Symposium.

Flavins and Flavoproteins. (1976). Singer T.P (ed.) Elsevier Scientific Publishing Company, $5^{\text {th }}$ International Symposium.

Frąckowiak D. \& Fiksiński K.(1976). Przekazywanie energii w jednostkach fotosyntetycznych. Post. Biochem., 22, 439465.

Frąckowiak D., Zelent B., Malak H., Planner A., Cegielski R., Munger G. \& Leblanc R.M. (1994). Fluorescence of aggregated forms of $\mathrm{Chl}$ a in various media, J. Photochem. Photobiol. A: Chem. 78, 49-55.

Frąckowiak D., Dudkowiak A., Ptak A., Malak H., Gryczyński I. \& Zelent B. (1998). Fluorescence lifetimes of oriented green bacteria cells, cell fragments and oriented bacteriochlorophyll c molecules, J. Photochem. Photobiol. B: Biol. 44, 231-239.

Fukushima Y., Okajima K., Shibata Y., Ikeuchi M. \& Ithon S. (2005). Primary intermediate in the photocycle of a bluelight sensory BLUF FAD-protein, TII0078, of Thermosynechococcus elongatus BP-1. Biochemistry, 44(13), 5149-5158.

Gabryś H. (1985). Chloroplast movement in Mougeotia induced by blue light pulses, Planta 166: 134-140.

Gabryś H., Walczak T. \& Haupt W. (1985). Interaction between phytochrome and the blue light photoreceptor system in Mougeotia. Photochem. Phoptobiol., 42(6), 731734.

Gabryś H. (1986). Dwa układy fotoreceptorowe sterujące ruchem chloroplastu w glonie Mougeotia. Post. Biol. Komórki, 13(1), 35-50.
Galland P. \& Lipson E.D. (1985). Action spectra for phototropicbalance in Phyomyces blakesleeanus: dependence on reference wavelength and intensity range. Photochem. Photobiol., 41, 323-329.

Gauden M., Yremenko S., Laan W., van Stokkum I.H.M., Ihalainem J.A., van Grondelle R., Hellingwerf K.J. \& Kennis J.T.M. (2005). Photocycle of the flavin-binding photoreceptor AppA, a bacterial transcriptional antirepressor of photosynthesis genes. Biochemistry, 44(10): 3654-3662.

Gibson Q.H., Massey V. \& Atherton N.M. (1962). The nature of compounds present in mixture of oxidized and reduced flavin mononucleotides. Biochem J., 85, 369-383.

Grabe B. 1974. Semi-empirical calculations on lumiflavin regarding electronic structure and spectra. Acta Chem. Scand., Ser.A, 28, 363-374.

Grajek H., Drabent R., Żurkowska G. \& Bojarski C. (1984). Absorption of the flavin dimers. Biochim. Biophys. Acta, 801, 456-460.

Grajek H., Żurkowska G., Drabent R., \& Bojarski C. (1986). The structure of the flavomononucleotide dimer. Biochim. Biophys. Acta 881, 241-247.

Grajek H., Żurkowska G., Bojarski C. \& Drabent R. (1990). Investigations of the fluorescence concentration quenching of flavomononucleotide in glycerine-water solutions. Photochem. Photobiol., 51, 565-571.

Grajek H., Żurkowska G., Bojarski C. \& Drabent R. (1992) The influence of fluorescence concentration quenching on the emission anisotropy of flavins in glycerine-water solutions. Photochem. Photobiol., 55, 381-387.

Grajek H., Żurkowska G., Bojarski P., Kukliński B., Smyk B., Drabent R. \& Bojarski C. (1998). Spectroscopic manifestations of flavomononucleotide dimers in polyvinyl alcohol films. Biochim. Biophys. Acta, 1384, 253-267.

Grajek H., Żurkowska G., Drabent R. \& Bojarski C. (2001). The effect of temperature and concentration on the aggregation of flavomononucleoyide iu aqueous solutions. Asian J. Spectroscopy, 2, 49-55.

Grajek H. (2003). The effect of temperature on FMN absorption spectra in rigid poly(vinyl alcohol) matrics. Biochim. Biophys. Acta, 1620, 133-138.

Grajek H., Żurkowska G., \& Kuśba J. (2005). Influence of diffusion on nonradiative energy transfer between FMN molecules in aqueous solutions. Biochim. Biophys. Acta, 80(2), 145-155.

Grajek H. (2007). Nonradiative rxcitation energy transfer processes between monomeric and fluorescent dimmers of flavin mononucleotide (FMN) in rigid systems. Rozprawy $i$ monografie. Wyd.UWM, 119, 1-159.

Grajek H., Liwo A., Wiczk W. \& Żurkowska G. (2007a). Resolution of the excitation- emission spectra of FMN in rigid poly(vinyl alcohol) matrices. J. Photochem. Photobiol. B: Biol., 86, 193-198.

Grajek H., Gryczyński I., Bojarski P., Gryczyński Z., Bharill S. \& Kułak L. (2007b) Flavin mnononucleotide fluorescence intensity decay in concentrated aques solutions. Chem. Phys. Lett. 439, 151-156.

Gruszecki W.I., Gagoś M. \& Kernen P. (2002). Polyene antibiotic amphotericin $\mathrm{B}$ in monomolecular layers: spectrophotometric and scanning force microscopic analysis. FEBS Lett., 524, 92-96.

Gruszecki W.I., Gagoś M. \& Hereć M. (2003a). Dimers of polyene antibiotic amphotericin $\mathrm{B}$ detected by means of 
fluorescence spectroscopy: molecular organization in solution and in lipid membranes. J. Photochem. Photobiol. B: Biol., 69, 49-57.

Gruszecki W.I., Gagoś M., Hereć M. \& Kernen P. (2003b). Organization of antibiotic amphotericin B in model lipid membranes. A mini review. Cell. Mol. Biolo. Lett., 8, 161170.

Guo H., Duong H., Ma N. \& Lin C. (1999). The Arabidopsis blue light receptor cryptochrome 2 is a nuclear protein regulated by a blue light-dependent posttranscriptional mechanism. Plant J, 19(3), 279-287.

Guo F., Chang B.H. \& Rizzo C.J. (2002). An N1-hydrogen bonding model for flavin coenzyme. Bioorg.Med. Chem. Lett., 12, 151-154.

Harders H., Förster S., Voelter W. \& Bacher A. (1974). Problems in electronic state assignment based on circular dichroism. Optical activity of flavines and 8-substituted lumazines. Biochemistry, 13(16), 3360-3364.

Haupt W., Wagner G. (1984). Membranes and Sensory Transduction [In:]. G. Colombeti,\& Lenci F. (eds.). Plenum Press, New York, pp. 331-375.

Heelis P.F., Parsons B J., Phillips G.O. \& McKellar J.F. (1978). A laser flash photolysis study of the nature of flavin mononucleotide triplet states and the reactions of the neutral form with amino acids. Photochem. Photobiol., 28, 169-173.

Heelis P.F. (1982). The photophysical and photochemical properties of flavins (isoalloxazines). Chem. Soc. Rev. 11(1), 15-39.

Jarillo J.A., Gabryś H., Capel J., Alonso J.M., Ecker J.R. \& Cashmore A.R. (2001). Phototropin-related NPL1 controls chloroplast relocation induced by blue light. Nature, 410, 952-954.

Johansson L.B.A., Davidson A., Lindblom G. \& Naqvi K.R. (1979). Electronic transitions in the isoalloxazine ring and orientation of flavins in model membranes studied by polarized light spectroscopy. Biochemistry, 18(19), 42514253.

Kainosho M. \& Kyogoku Y. (1972). High-resolution proton and phosphorus nuclear magnetic resonance spectra of flavin-adenine dinucleotide and its conformation in aqueous solution. Biochemistry, 11(5), 741-752.

Kasahara M., Swartz T.E., Olney M.A., Onodera A., Mochizuki N., Fukuzawa H., Asamizu E., Tabata S., Kanegae H., Takano M., Christie J.M., Nagatani A. \& Briggs W.R. (2002). Photochemical properties of the flavin mononucleotide-binding domains of the phototropins from Arabidopsis, rice, and Chlamydomonas reinhardtii. Plant Physiol., 192(2), 762-773.

Kautsky H. \& de Bruijn H. (1931). Die Aufklärung der Photoluminescenztilgung fluorescierender Systeme durch Sauerstoff: Die Bildung aktiver, diffusionsfähiger Sauerstoffmoleküle durch Sensibilisierung. Naturwiss.,19, $1043-1052$.

Kitizing K., Fitzpatrick T.B., Wilken C., Sawa J., Bourenkov G.P., Macheroux P. \& Clausen T. (2005). The $1.3 \AA$ crystal structure of the flavoprotein YqjM reveals a novel class of old yellow enzymes. JBC, 280, 27904-27913.

Kottke T., Heberle J., Hehn D., Dick B. \& Hegemann P. (2003). Phot-LOV1: Photocycle of a blue-light receptor domain from the green Alga Chlamydomonas reinhardtii. Biophys. J., 84, 1192-1201.
Kowallik W. (1967). Action spectrum for an enhancement of endogenous respiration by light in Chlorella. Plant. Physiol., 42, 672-676.

Kowallik U. \& Kowallik W. (1969). Eine wellenlängenabhängige Atmungssteigerung während der Photosythese von Chlorella. Planta, 84, 141-157.

Kozioł J. (1966). Studies on flavins in organic solvents-II. Photodecomposition of riboflavin in the presence of oxygen. Photochem. Photobiol., 5, 55-62.

Kozioł J. (1969). Studies on flavins in organic silvents-III. Spectral behaviour of lumiflavin. Photochem. Photobiol., 9. 45-53.

Kraft B.J., Masuda S., Kikuchi J., Dragnea V., Tollin G., Zaleski J.M. \& Bauer C.E. (2003). Spectroscopic and mutational analysis of the blue-light fotoreceptor AppA: A novel photocycle involving flavin stacking with an aromatic amino acid. Biochemistry, 42, 6726-6734.

Kuhn R.,Weygand F. (1934). Synthese des 9-Methyl-isoalloxazins. Ber. Dtsch. Chem. Ges., 67, 1409-1412.

Kułak L. \& Bojarski C. (1995). Forward and reverse electronic energy transport and trapping in solution. I. Theory. Chem. Physics, 191, 43-66.

Lenci F., Colombetti G. \& Häder D.P. (1983). Role of flavin quenchers and inhibitors in the sensory transduction of negative phototaxis in the flagellate, Euglena gracilis. Curren Microbiol., 9, 285-290.

Lin C., Yang H., Guo H., Mockler T., Chen J. \& Cashmore A.R. (1998). Enhancement of blue- light sensitivity of Arabidopsis seedlings by a blue light receptor cryptochrome 2. Plant Biol., 95, 5, 2686-2690.

Lin C. (2000). Plant blue-light receptors. Trends Plant Sci., 5, 8, 337-342.

Lin C. \& Todo T. (2005). The cryptochromes. Genome Biol, 6(5), 220-226.

Liu B. Liu H., Zhong D. \& Lin.C. (2010). Searching for a photocycle of the cryptochrome photoreceptors. Current Option in Plant Biuol., 13, 578-586.

Löser G. \& Schäfer F. (1986). Are there several photoreceptors involved in phototropism of Phyomyces blakesleeanus? Kinetic studies of dichromatic irradiation, Photochem. Photobiol. 43(2), 195-204.

Lu C.Y. \& Liu Y.Y. (2002). Electron transfer oxidation of tryptohan and tyrosine by triplet states and oxidized radicals of flavin sensitizers: a laser flash photolysis study. Biochim. Biophys. Acta, 1571, 71-76.

Masuda S. \& Bauer C. E. (2002). AppA is a blue light photoreceptor that antirepresses photosynthesis gene expression in Rhodobacter sphaeroides. Cell, 110, 613-623.

Mieloszyk K., Drabent R.\& Mieloszyk J. (1989). Badania oddziaływania flawin $\mathrm{z}$ indolami metodami fluorescencyjnymi. Acta Acad. Agricult. Techn. Olst., Technologia Alimentorum, 23, 152-157.

Miura R., Setoyama C., Nishina Y., Shiga K., Miyahara I., Mizutani H. \& Hirotsu K. (2001). Porcine kidney d-amino acid oxidase: the three-dimensional structure and its catalytic mechanism based on the enzyme-substrate complex model. J. Mol. Catal., B Enzym., 12, 43-52.

Miura T., Maeda K. \& Arai T. (2003). Effect of Coulomb interaction on the dynamics of the radical pair in the system of flavin mononucleotide and hen egg-white lysozyme (HEWL) studied by a magnetic field effect. J. Phys. Chem. B. 107, 6474-6478. 
Muñoz M.A., Carmona C., Hidalgo J., Guardado P. \& Balón M. (1995). Molecular associations of flavins with betacarbolines and related indoles. Bioorg. Med. Chem., 3(1), 41-47.

Muralidhara B.K. \& Wittung-Stafshede P. (2003). Can cofactor-binding sites in proteins be flexible? Desulfovibrio desulfuricans. flavodoxin binds FMN dimer. Biochemisrty, 42, 13074-13080.

Müller F., Mayhew S.G. \& Massey V. (1973). On the effect of temperature on the absorption spectra of free and proteinbound flavines. Biochemistry, 12, 4654-4662.

Müller F. (1981). Spectroscopy and photochemistry of flavins and flavoproteins. Photochem. Photobiol., 34, 753-759.

Nakasako M., Matsuoka D., Zikihara K. \& Tokutomi S. (2005). Quaternary structure of LOV-domain containing polypeptide of Arabidopsis FKF1 protein. FEBS Lett., 579(5), 1067-1071.

Narayanasami R., Horowitz P.M. \& Master B.S.S. (1995). Flavin-binding and protein structural integrity studien on NADPH-cytochrome P450 reductase are consistent with the presence of distinct domains. Arch. Biochem. Biophys., 316, $1,267-274$.

Ninnemann H. (1980). Blue light photoreceptors, Bio Science 30. $166-170$.

Nowicki M., Susla B., Planner A. \& Frąckowiak D. (1999). The texture of stretched and unstretched polymer films with and without embedded biological matherials. Spectrosc. Lett., 32(4), 629-637.

Partch C.L., Clarkson M.W., Ozgur S., Lee A.L. \& Sancar A. (2005). Role of structural plasticity in signal transduction by the cryptochrome blue-light photoreceptor. Biochemistry, 44(10), 3795-805.

Penzer G.R. \& Radda G.K. (1976). The chemistry and biological functions of isoalloxazines (flavines). Quart. Rev.(London), 21, 43-65.

Presti D., Hsu W.J. \& Delbrück M. (1977). Phototropism in Phyomyces mutants lacking $\beta$-catotene. Photochem. Photobiol., 26, 403-405.

Quiñones M.A. \& Aparicio P.J. (1990). Flavin type action spectrum of nitrate utilization by Monoraphidium braunii. Photochem. Photobiol. 51, 689-692.

Sakai T., Kagawa T., Kasahara M., Swartz T.E., Christie J.M., Briggs W.R., Wada M. \& Okada K. (2001). Arabidopsis nph1 and nph1: Blue light receptors that mediate both phototropism and chloroplast relocation. PNAS, 98(12), 6969-6974.

Salomon M., Chistie J.M., Knieb E., Lempert U. \& Briggs W.R. (2000). Photochemical and mutational analysis of the FMN-binding domains of the plant blue light receptor, phototropin. Biochemistry, 39, 9401-9410.

Salomon M., Lempert U. \& Rüdiger W. (2004). Dimerization of the plant photoreceptor phototropin is probably mediated by the LOV1 domain. FEBS Lett., 572(1-3), 8-10.

Sarma R.H., Dannies P. \& Kaplan N.O. (1968). Investigations of inter- and interamolecular interactions in flavin-adenine dinucleotide by proton magnetic resonance. Biochemistry, 7(12), 4359-4367.

Schmidt W. (1984). The study of basic photochemical and photophysical properties of membrane-bound flavins: The indispensible prerequisite for the elucidation of primary physiological blue light action. [In:] The blue light effects in biological systems. Senger H. (ed.) Springer-Verlag, BerlinHeidelberg, New York, pp.81-94.

Schüttrigkeit T.A., Kompa C.K., Salomon M., Rüdiger W. \& Michel-Beyerle M.E. (2003). Primary photophysics of the FMN binding LOV2 domain of the plant blue light receptor phototropin of Avena sativa. Chem. Phys., 294, 501-508.

Scola-Nagelschneider G. \& Hemmerich P. (1972). Circular dichroism, self interaction and side chain conformation of riboflavin and riboflavin analogues. Z. Naturforsch., 27b, 1044-1046.

Siódmiak B.\& Drabent R. (1973). Spectral investigations of riboflavine phototransformation in anisotropic medium. A44(5), 659-669.

Siódmiak J. \& Frąckowiak D. (1972). Polarization of fluorescence of riboflavin in anisotropic medium. Photochem. Pchotobiol., 16:, 73-182.

Smyk B. \& Grajek H. (2001). Conformation of FMN dimer obtained by molecular modelling methods. Current Topics in Biophys. 25(2), 81-84.

Song P.S. (1969a). Electronic structures and spectra of flavins: an improwed Pariser-Parr-Pople MO and semiempirical unrestricted Hartree-Fock Computations. Ann. N.Y. Acad. Sci., 158. 410-423.

Song P.S. (1969b). Theoretical considerations of the electronic spectra of methyl flavins. Int. J. Quant. Chem., 3, 303-316.

Song P.S. (1971). Chemistry of flavins in their excited states. [In:] Kamin H. (ed. ). Flavins and Flavoproteins, Third International Symposium,. University Park Press, Baltimore. pp. 37-61.

Song P.S., Moore T.A. \& Kurtin W.E. (1972a) 1. Molecular luminescence studies of flavins, II Interactions involving the excited states. Z. Naturforsch. 27, 1011-1015.

Stryer L. (1995) [In:] Freeman W. H..\& Co (eds.) Biochemistry, New York.

Sujak A., Okulski W. \& Gruszecki W.I. (2000). Organisation of xanthophyll pigments lutein and zeaxanthin in lipid membranes formed with dipalmitoylphosphatidylcholine. Biochim. Biophys. Acta, 1509, 255-263.

Sun M., Moore T.A. \& Song P.S. (1972). Molecular luminescence studies of flavins. I. The excited states of flavins. J. Am.Chem. Soc., 94(5), 1730-1740.

Sun M. \& Song P.S. (1973). Excoted states a reactivity of 5_Deazaflavine. Comparative studies with flavine. Biochemistry, 12, 4663-4669.

Swartz T.E., Corchnoy S.B., Christie J.M., Lewis J.W., Szundi I., Briggs W.R. \& Bogomolni R.A. (2001). The photocycle of a flavin-binding domain of the blue light photoreceptor phototropin. J.Biol. Biochem., 276(39), 36493-36500.

Tollin G. (1968). Molecular complexes of flavins. [In:] Pullman B.(ed.) Molecular associations in biology. Academic Press, New York and London, pp. 393-409.

Tsentalovich Y.P., Lopez J.J., Hore P.J. \& Tagdeev R.Z. (2003). Mechanisms of reactions of flavin mononucleotide triplet with aromatic amino acids. Spectrochimica Acta A, 58, 2043-2050.

Turck F., Fornara F. \& Coupland G. (2008). Regulation and identity of florigen: flowering locust moves center stage. Annu Rev. Plant Biol. 59, 573-594.

Tyagi A., Penzkofer A., Mathes T. \& Hegemann P. (2010). Photophysical characterisation and phot-cycle dynamics of LOV1-His domain of phototropin from Chlamydomonas 
reinhardtii with roseoflavin monophosphate cofactor, J. Photochem. Photobiol B: Biology, 101, 76-88.

Ulbrych K. (1979). Kompleksy z przeniesieniem ładunku ryboflawina - tryptofan i ryboflawina - hydrochinon $\mathrm{w}$ roztworze wodnym. Zesz. nauk. ART. Olszt. Technologia Żywności, 15, 3-14.

Ulbrych K. \& Siódmiak J. (1982). Wygaszanie fluorescencji ryboflawiny przez hydrochinion w roztworach wodnych. Zesz. Nauk. ART. Olszt. Technologia Żywności, 17, 55-61.

Visser A.J.W.G., Ommen G.J., Ark G., Müller F. \& Voorst J.D.W. (1974). Laser photolysis of 3-metyllumiflavin. Photochem. Photobiol., 20, 227-232.

Visser A.J.W.G. (1984). Kinetics of stacking interactions in flavin adenine dinucleotide from time-resolved flavin fluorescence. Photochem. Photobiol. 40(6), 703-706.

Walczak T., Gabryś H. \& Haupt W. (1984). Flavin-mediated weak-light chloroplast movement in Mougeotia, [In:] Senger H. (ed.) Blue Light Effect in Biological Systems, SpringerVerlag, Berlin - Heidelberg, pp. 454-459.

Weber G. (1948). The quenching of fluorescence in liquids by complex formation. Determination of the mean life of the complex. Trans.Faraday Soc., 44, 185-189

Whitelam G. (1995). A green light for cryptochrome research. Curr. Biol., 5(12), 1351-1353.

Zhu H. \& Green C.B. (2001). A putative flavin electron transport pathway is differentially utilized in Xenopus CRY1 and CRY2. Curr. Biol., 11(24), 1945-1949.

Zirak P., Penzkofer A. Hegemann P. \& Mathes T. (2007). Photo dynamics of BLUF domain mutant H44R of AppA from Rhodobacter sphaeroides. Chem. Phys. 355, 15-27.

Zurzycki J. (1962) The action spectrum for the light depended movements of chloroplasts in Lemna trisulca $\mathrm{L}$. Botanic.Pol. 31, 3, 489-538.

Zurzycki J. (1975). Rola błon w procesie fotorecepcji. Post. Biol. Komórki, 2(1), 61-85.

Żurkowska G., Grajek H. \& Bojarski C. (1996). Effect of concentration and excitation wavelength on fluorescent spectra of flavomononucletide in polyvinyl alcohol films, Current Topics in Biophys. 20(2), 134-138. 